\title{
A cohort study of chronic diseases in a random sample of newly arrived refugees to Southeast Michigan, US
}

\author{
Hikmet Jamil $^{1 *}$, Judith Arnetz ${ }^{1,2}$, Joel Ager ${ }^{3}$, Mark A. Lumley ${ }^{4}$, Nnamdi Pole ${ }^{5}$ and Bengt Arnetz ${ }^{1,2}$ \\ ${ }^{1}$ Department of Family Medicine, College of Human Medicine, Michigan State University, East Lansing, Michigan, USA \\ ${ }^{2}$ Department of Public Health and Caring Sciences, Uppsala University, Uppsala, Sweden. \\ ${ }^{3}$ Department of Family Medicine and Public Health Sciences, Wayne State University. Michigan, USA \\ ${ }^{4}$ Department of Psychology, Wayne State University, Detroit, Michigan, USA \\ ${ }^{5}$ Department of Psychology, Smith College, Northampton, Massachusetts, USA
}

\begin{abstract}
This cohort study tests if there were differences in the prevalence rate of ten chronic diseases (CD) and self-rated health (SRH) between a two year follow-up. If differences existed, risk factors were identified. Random samples of 298 Iraqi refugees were interviewed to complete a survey related to relevant questionnaires. There was a significant difference between the studied periods for each CD and SRH. Risk factors of each CD and SRH were predicted. We conclude that our hypothesis, which predicted that Iraqi refugees would report a similar prevalence rate of $\mathrm{CD}$ and better health over the three periods studied, was rejected.
\end{abstract}

\section{Introduction}

According to the Department of Homeland Security, the United State of America (US) has received more than 88,000 Iraqi refugees between 1994 and 2013 [1]. Previous research on refugee health has mainly focused on mental health disorders, with less emphasis on chronic diseases (CD). Some of the limitations of these studies include utilizing a cross sectional study based simply on convenience samples; and have often been conducted several years after refugees arrive in the US, or other host country. Literature review reveals discrepancies in the prevalence rate of $\mathrm{CD}$ among refugees in different parts of the world [2-9]. However, refugee health studies reveal that the prevalence of some CD (heart diseases, hypertension and diabetes) among American refugees could be higher or lower compared to the US norm population or even from other subsets of refugees $[2,6,8,10,11]$.

Chronic diseases (CD) account for a considerable disease burden among all screened Iraqi refugees [12-15]. One study showed that $27 \%$ of Iraqi refugees screened by the International Organization for Migration (IOM) clinic in Jordan had at least one CD; the prevalence of some notable $\mathrm{CD}$ were $33 \%$ hypertension, $3 \%$ diabetes, and $34 \%$ obesity [14]. Among adult Iraqi refugees screened in California, the most commonly diagnosed CD were obesity (25\%), hypertension (15\%), and asthma (2\%) [16]. A study in California [17] showed that around half of the adult refugees in this sample had at least one CD (51.1\%). It is worth noting that chronic disease is somewhat more common among Iraqi adults and older immigrants in general [18].

One study of health outcomes of Gulf War among Iraqis reported a higher prevalence of multiple somatic disorders, including: skin, musculoskeletal disorders (MSDs) and arthritis, among soldiers compared with civilians [19]. Chemical exposures and psychological stressors are the two main etiologies that are believed to explain the increase in medical conditions (E.g. skin, MSDs and arthritis among
Gulf war veterans [20-25]. Veterans who served in the Gulf War were exposed to many potential chemical hazards and psychological stressors, which could have attributed to adverse chronic health illnesses, including skin disorders [26-29]. In general, veterans have reported all of the above chronic conditions studied in this study in higher percentages than the general population [30,31].

In the US, nearly half of the general population has at least one CD [32]. The prevalence rates of some CD among the US population are as follows: $20.9 \%$ for Hypertension, where females had higher prevalence [33], 6.0\% for Heart Disease, higher in men [34], 8.3\% for Diabetes mellitus, higher among males [35], 8.5\% for Asthma, higher among females [36], 22.0\% for Arthritis, higher among females [37],29 to 34\% for MSDs, higher among females [38], 19\%-22\% for Skin disorders, higher among females [39], 31.7\% for high cholesterol [40], 21\%-35\% for Obesity [41], and 6.7\% for depression [42].

Reviewing available studies will lead to a better understanding of newly arriving refugee's health status. There is also much to learn from our study on refugee's health, as it is the first cohort study on $\mathrm{CD}$ among newly arrived refugees to the US. The objectives of the study are: (A) To examine the pattern of the ten CD (Hypertension, Heart disease, Diabetes, Asthma, Arthritis, Musculoskeletal disorders (MSDs), Skin disorders, high cholesterol level, obesity and depression) in the two year period studied, and compare to baseline data (BLD. We

Correspondence to: Hikmet Jamil, MD, DVD, DIH, MSc, PhD, College of Human Medicine,Michigan State University, Michigan, USA, Tel: (313) 3091645, Fax: (313) 309-1676; E-mail: hikmet.jamil@hc.msu.edu

Key words: Gender, trauma in US, chronic diseases, self-rated health, Iraq Received: March 04, 2016; Accepted: March 23, 2016; Published: March 28, 2016 
hypothesize that there will be no differences in the pattern of any of the ten $\mathrm{CD}$ within the two year period studied and the base line data; (B) To examine the prevalence rate of each of the ten CD as well as combinations of these diseases, and to predict the risk factors for each of these diseases or combinations of the ten diseases. We hypothesize that there will be no difference in the prevalence rate of any of these ten diseases or in the combination of these diseases, in a random sample of newly arrived Iraqi refugees to the US because the study period is relatively short, which will make it difficult to study progression of CD.

\section{Methods}

The prevalence of each CD studied (hypertension, heart disease, diabetes mellitus, asthma, arthritis, MSDs and skins, skin disease, high cholesterol level, obesity and depression) was determined based on a random sample of newly arrived Iraqi refugees to the US, and on follow up data over the next two years. The study data was already used in several published papers [43-47]. The study population (refugees) was chosen randomly from several lists of codes numbers (each code represents one refugee) that were provided by several refugee resettlements agencies in Southeast Michigan (E.g. Lutheran Social Services of Michigan), and based on the recruitment criteria given to these agencies (Age 18 years to 57 years, recently arrived to US, i.e. less than one year). These codes were entered into SPSS and 35\% were randomly selected.

The procedure is as follows: A bilingual Arabic-English psychiatrist conducted structured face-to face interviews with participants, taking place mainly in participants' homes or in community organizations. The first interview occurred, on average, about one month after arrival in the US. The second interview occurred nearly one year after arrival. The third interview occurred nearly two years after arrival. Withdrawal of the participants from the study over time was very low; seven participants withdrew between baseline and follow-up (97.7\% retention rate), and an additional five participants withdrew from follow-up to $2^{\text {nd }}$ follow-up ( $n=286,97 \%$ retention rate over the three year followup). It is worth noting that some participants declined to respond to all questions, and thus there was some data missing. In order to include as much of the sample as possible, participants were included for all analyses where they had complete data. This is reflected in Tables 1-3 having different sample sizes in each year studied.

The survey questionnaires included different standardized instruments in addition to the basic demographic questions, which were adopted from the National Health Interview Survey [48]. Thirteen questions were asked about medical conditions; ten relating to major CD were included in this study. One example is: "Has your primary health care physician informed you that you have (BLANK) disease?" in which the 13 possible diseases were listed for the participant to choose as applies, with either "yes" or "no" to each question. The sociodemographic information used included age, gender, marital status, educational level, length of time in the US, employment status and health insurance status. Other variables were also included such as whether or not participants smoked hookah, or other forms of tobacco. The "Alcohol drink variable" included whether participants drink alcohol or not.

To measure pre-migration trauma (Back home trauma), we used a Pre-displacement trauma exposure scale; it was measured using the Harvard Trauma Questionnaire (HTQ), Arabic version $[49,50]$. Participants responded either "yes" or "no" to each of 39 traumatic experiences questions. Responses were added to create a HTQ cumulative trauma sum score ranging from 0 to 39. Cronbach's alpha for the HTQ scale was 0.912 at BLD. After the refugees enter the US, we modified the HTQ to what we called "Trauma in US" as we excluded some of the HTQ because it was not relevant to be asked to the refugees. Cronbach's alpha for trauma in US was 0.625 at BLD, 0.332 at Y1 and 0.434 at Y2. Then we created what we called "Daily life problems" scale which contained the following measures: (A) Boredom scale as one of the post-migration living difficulties, which may be associated with depression, anxiety and somatization [50]. Boredom was measured by a single item: "In a typical day, how often do you feel boredom" which was rated on a 5-point scale ranging from 1 (Almost never) to 5 (Almost always); (B) Hassles scale [51], was measured using a 5 degree Likert scale ranging from "Almost never" to "Almost always". Participants were asked about the frequency with which they experienced problems with various potential daily hassles. Each participant was assigned a score from 1 to 5 where a higher score

Table 1: Percentage of the demographic variables by gender among Iraqi Refugees in the period studied with test of significant.

\begin{tabular}{|c|c|c|c|c|c|c|c|c|c|}
\hline \multirow{2}{*}{ Variable } & \multicolumn{3}{|c|}{ Baseline } & \multicolumn{3}{|c|}{ Y1 } & \multicolumn{3}{|c|}{ Y2 } \\
\hline & Male $(n=161)$ & Female $(n=137)$ & total $(n=298)$ & Male $(n=159)$ & Female $(n=132)$ & total $(n=291)$ & Male $(n=152)$ & Female $(n=134)$ & total $(n=286)$ \\
\hline Married & 48.4 & 55.5 & 51.7 & 48.4 & 59.1 & $53.3^{*}$ & 50.0 & 63.4 & $56.2 *$ \\
\hline H.S. or less & 68.9 & 74.5 & 71.5 & 65.4 & 74.2 & 69.4 & 68.4 & 74.8 & 71.4 \\
\hline Employed & 1.2 & 2.2 & 1.68 & 67.3 & 28.0 & $49.5^{*}$ & 72.4 & 40.8 & $58.1 *$ \\
\hline Have Health Ins. & 21.7 & 27.7 & 24.5 & 100.0 & 100.0 & 100.0 & 42.8 & 57.6 & $49.6^{*}$ \\
\hline Smoker & 65.2 & 7.3 & $38.6^{*}$ & 70.4 & 7.6 & $41.9^{*}$ & 73.0 & 8.4 & $43.1^{*}$ \\
\hline Drink alcohol & 37.3 & & 20.1 & 69.2 & 5.3 & $40.3^{*}$ & 86.2 & 8.4 & $50.2 *$ \\
\hline SRH/Fair to Poor & 78.3 & 71.5 & 75.2 & 74.2 & 65.9 & 70.4 & 72.4 & 71.8 & 72.1 \\
\hline Continuous Variable & $\mathrm{M}(\mathrm{SD})$ & $\mathrm{M}(\mathrm{SD})$ & $\mathrm{M}(\mathrm{SD})$ & $\mathrm{M}(\mathrm{SD})$ & $\mathrm{M}(\mathrm{SD})$ & $\mathrm{M}(\mathrm{SD})$ & $\mathrm{M}(\mathrm{SD})$ & $\mathrm{M}(\mathrm{SD})$ & $\mathrm{M}(\mathrm{SD})$ \\
\hline Age & $33.2(11.6)$ & $33.7(11.0)$ & $33.4(11.3)$ & $33.8(1.9)$ & $34.8(11.0)$ & $34.3(11.4)$ & $35.1(11.4)$ & $35.8(10.9)$ & $35.4(11.1)$ \\
\hline Months in US & $0.0(1.0)$ & $1.1(1.2)$ & $1.0(1.1)$ & $12.5(1.1)$ & $12.6(1.2)$ & $12.5(1.1)$ & $24.8(1.3)$ & $24.8(1.8)$ & $24.8(1.5)$ \\
\hline Current Stressor & $1.2(0.4)$ & $1.2(0.5)$ & $1.2(0.5)$ & $1.7(0.9)$ & $1.8(1.0)$ & $1.8(0.9)$ & $1.7(0.9)$ & $1.5(0.8)$ & $1.6(0.8)$ \\
\hline Daily life problems & $27.8(4.1)$ & $28.1(3.8)$ & $27.9(3.9)$ & $33.2(6.1)$ & $33.9(5.6)$ & $33.5(5.9)$ & $40.1(6.6)$ & $41.3(7.5)$ & $40.6(7.1)$ \\
\hline Trauma in US & & & & $1.4(0.9)$ & $1.4(0.9)$ & $1.4(0.9)$ & $2.2(1.2)$ & $2.1(1.3)$ & $2.1(1.3)$ \\
\hline Back home trauma* & $13.5(3.65)$ & $11.4(2.97)$ & $12.6(3.51)$ & & & & & & \\
\hline
\end{tabular}

Note: To make $100 \%$ of the variables reported consider the following: Single/divorce/widow/separate, Higher than high school or less, Unemployed, No health insurance. Never smoke and Never drink. ${ }^{*}$ P range between $<0.05-0.001$ 
Table 2: Prevalence of ten chronic diseases studied (CD) among Iraqi Refugees by gender in each period studied.

\begin{tabular}{|c|c|c|c|c|c|c|c|c|c|}
\hline \multirow[t]{2}{*}{ CD } & \multicolumn{3}{|c|}{ Baseline } & \multicolumn{3}{|c|}{ Y1 } & \multicolumn{3}{|c|}{ Y2 } \\
\hline & Male $(n=161)$ & Female $(n=137)$ & total $(\mathrm{n}=298)$ & Male $(n=159)$ & Female $(n=132)$ & total $(n=291)$ & Male $(\mathrm{n}=152)$ & Female $(n=134)$ & total $(n=286)$ \\
\hline Hypertension & 12.4 & 6.6 & 9.7 & 16.4 & 9.8 & 13.4 & 17.8 & 11.5 & 14.9 \\
\hline Heart disease & 3.1 & 3.6 & 3.4 & 4.4 & 2.3 & 3.4 & 5.3 & 3.8 & 4.6 \\
\hline Diabetes & 5.6 & 3.6 & 4.7 & 5.7 & 6.8 & 6.2 & 7.2 & 8.5 & 7.8 \\
\hline Asthma & 2.5 & 5.1 & 3.7 & 2.5 & 4.5 & 3.4 & 3.3 & 6.1 & 4.6 \\
\hline Arthritis & 18.0 & 19.0 & 18.5 & 20.1 & 25.0 & 22.3 & 23.0 & 29.8 & 26.1 \\
\hline MSDs & 8.1 & 10.9 & 9.4 & 20.1 & 25.0 & 22.3 & 27.0 & 28.2 & 27.6 \\
\hline Skin disorders & 7.5 & 5.8 & 6.7 & 6.9 & 7.6 & 7.2 & 7.9 & 8.5 & 8.2 \\
\hline$>$ Cholesterol & 9.3 & 5.8 & 7.7 & 18.9 & 13.6 & 16.5 & 23.0 & 19.8 & 21.6 \\
\hline Obese & 21.1 & 19.0 & 20.1 & 21.4 & 19.8 & 20.7 & 22.4 & 27.1 & 24.6 \\
\hline Depressive & 0.6 & 0.7 & 0.7 & & 6.1 & 2.8 & 1.4 & 7.6 & 4.2 \\
\hline \multicolumn{10}{|c|}{ Frequency of Combined all diseases } \\
\hline No disease & 54.0 & 59.9 & 56.7 & 50.9 & 50.8 & 50.9 & 44.1 & 41.2 & 42.8 \\
\hline One Disease & 23.0 & 19.7 & 21.5 & 22.0 & 19.7 & 21.0 & 23.7 & 21.4 & 22.6 \\
\hline Two Diseases & 10.6 & 5.8 & 8.4 & 9.4 & 9.1 & 9.3 & 13.8 & 11.5 & 12.7 \\
\hline Three + diseases & 12.4 & 14.6 & 13.4 & 17.6 & 20.5 & 18.9 & 18.3 & 26.0 & 21.9 \\
\hline
\end{tabular}

There were no significant differences between gender and any single diseases except in depression for Y1 and Y2.There were significant differences ( $\mathrm{P}<0.001)$ between any two periods test for each diseases as well as for all disease combined.

Table 3: Linear regression analysis: Showing only significant risk factors for combined Ten CD and SRH in each period studied.

\begin{tabular}{|c|c|c|c|c|c|c|}
\hline \multirow[t]{2}{*}{ Linear regression analysis } & \multirow{2}{*}{$\begin{array}{c}\text { Standardized coefficients } \\
\text { Beta }\end{array}$} & \multirow[t]{2}{*}{$\mathbf{t}$} & \multirow[t]{2}{*}{ Sig. } & \multicolumn{2}{|c|}{$95.0 \%$ C. I. for OR } & \multirow[t]{2}{*}{ Partial } \\
\hline & & & & Lower & Upper & \\
\hline \multicolumn{7}{|c|}{ Only predict risk factors in each $\mathrm{CD}$ analysis } \\
\hline \multicolumn{7}{|c|}{ Dependent variable: BLD for all CD } \\
\hline Age & 0.6 & 10.2 & 0 & 0.05 & 0.08 & 0.52 \\
\hline More than H.S & -0.12 & -2.39 & 0.017 & -0.58 & -0.06 & -0.14 \\
\hline \multicolumn{7}{|c|}{ Dependent variable: $\mathrm{Y} 1$ for all $\mathrm{CD}$} \\
\hline Age & 0.51 & 9.08 & 0 & 0.06 & 0.09 & 0.48 \\
\hline Employed & -0.12 & -2.02 & 0.044 & -0.77 & -0.01 & -0.12 \\
\hline Daily life problems & 0.15 & 2.39 & 0.018 & 0.01 & 0.08 & 0.14 \\
\hline Trauma in US & 0.11 & 2.29 & 0.023 & 0.03 & 0.41 & 0.14 \\
\hline \multicolumn{7}{|c|}{ Dependent variable: $\mathrm{Y} 2$ for all $\mathrm{CD}$} \\
\hline Age & 0.49 & 9.73 & 0 & 0.06 & 0.1 & 0.51 \\
\hline Employed & -0.27 & -4.95 & 0 & -1.37 & -0.59 & -0.29 \\
\hline Trauma In US & 0.18 & 3.74 & 0 & 0.12 & 0.39 & 0.22 \\
\hline \multicolumn{7}{|c|}{ Only predict risk factors in each SRH analysis } \\
\hline \multicolumn{7}{|c|}{ Dependent variable: BLD for SRH } \\
\hline Age & -0.21 & -2.7 & 0.007 & -0.02 & 0 & -0.16 \\
\hline All CD & -0.13 & -1.96 & 0.05 & -0.12 & 0 & -0.12 \\
\hline \multicolumn{7}{|c|}{ Dependent variable Y 1 for SRH } \\
\hline Single/Divorce/Widow/Separate & 0.13 & 1.98 & 0.048 & 0 & 0.29 & 0.12 \\
\hline Smoker & 0.19 & 2.42 & 0.016 & 0.04 & 0.37 & 0.14 \\
\hline \multicolumn{7}{|c|}{ Dependent variable: $\mathrm{Y} 2$ for SRH } \\
\hline Daily life problems & -0.18 & -2.51 & 0.013 & -0.02 & 0 & -0.15 \\
\hline
\end{tabular}

Variables in the equation: age, gender, marital status, education level, occupation, health insurance, current stressor, trauma in US, daily life problems, tobacco status, alcohol status, back home trauma for BLD, all CD combined for Y1 and Y2 analysis

indicates more problems; (C) Discrimination scale used a 5-point Likert scale ranging from 1 (Almost never) to 5 (Almost always), so that higher scores indicate more positive discrimination. Cronbach's alpha for the daily life problems scale (variable: A, B, C) was 0.816 at BLD, 0.809 at $\mathrm{Y} 1$ and 0.716 at $\mathrm{Y} 2$. The current stressor (based on a Likerttype scale, a 5-point scale ranging from 1(Not at all) to 5 (Extremely), used higher scores to indicate more positive stressor.

The prevalence of each CD was tested at the BLD and for each of the two-year follow-up data by the Pearson's chi-squared test, to compare male versus female data of the refugees. T-tests were used to compare all continuous variables (age, time in the US, back home trauma, trauma in IS, current stressor and daily life problems) between males and females. Binary logistic regression modeling was used to more understanding predictors of risk factor for each $\mathrm{CD}$ reported in $\mathrm{Y} 2$. The independent variable entered into the equation model was that of the Y2 data plus the back home trauma variable which was reported at 
BLD. Linear regression modeling was used for all CD combined. Once for each period studied, the independent variables were entered into the equation modeling for each period studied. However, employment status and health insurance variables were not included in the model at BLD analysis because $96 \%$ of the refugees were not employed, and also because all refugees have health insurance (Medicaid) during the first 8 months of their arrival. Statistically we controlled for known risk factors as well as baseline back home trauma exposures.

Questions on self-rated health (SRH) were based on a Likert-type scale; a 5-point scale ranging from 1 (Excellent) to 5 (poor) was used. SRH was tested by linear regression analysis for each period study to predict risk factors for excellent health in each period. The same independent variables used for testing the all CD in each period were used in addition to all CD for each period studied. Significance was set to a p-value of less than .05. The IBM SPSS statistics program (version 23) was used for all data analyses. This study was approved by the Human Investigation Committee at Wayne State University, Detroit, Michigan.

\section{Results}

In the study follow-up of the prevalence rate of CD among 298 Iraqi refugees for two-year periods, the mean age was $33.4(\mathrm{SD}=11.3)$. Males constituted $54 \%$ of the study. The prevalence rate of combined CD at arrival (BLD) was $43.3 \%$. It rose to $49.1 \%$ in Y1 then to $57.2 \%$ in $\mathrm{Y} 2$. The percentage of participants who reported fair to poor health at BLD was $75.2 \%$, it decline to $70.4 \%$ in Y2 but it rose again to 72.1 in Y2. Table 1 shows a percentage of demographic and other variables of refugees in the BLD and the two-year follow-up data, classified by gender. In general there were no significant differences between males and females except in the following variables: marital status and employment status in Y1 and Y2, health insurance in Y2. Smoking status and alcohol drinking status were significantly different in the three periods studied. T-test for continuing variables scaling reveals no significant differences between males and females except in back-home trauma at BLD. Table 2 indicates a significant difference $(\mathrm{P}<0.001)$ between any two periods for each disease irrespective of participant's gender, except depression, where the difference was significant between any two period.

Table 2 also shows the frequency of all CD studied in the three-year period by gender. It is notable that the number of participants without any CD did decrease: it was $56.7 \%$ in BLD and fell to $51 \%$ in Y1, then to $42.8 \%$ in Y2. Those who reported three or more diseases increased from $13.4 \%$ in BLD to $18.9 \%$ in Y1, and $21.9 \%$ in Y2. Linear regression analysis (table 3 ) reveals the overall regression for the all $\mathrm{CD}$, which proved significant for each of the three years studied (for BLD, $\mathrm{R}=0.321$, $\mathrm{F}=16.526, \mathrm{P}<0.000$. However, for $\mathrm{Y} 1, \mathrm{R}=0.404, \mathrm{~F}=18.452, \mathrm{P}<0.000$ ), for $\mathrm{Y} 2, \mathrm{R}=0.492, \mathrm{~F}=23.203, \mathrm{P}<0.000$ ), the predicting risk factors of likelihood all CD in each of the three periods studied were as follows:

- Age was a risk factors in all period studied,

- Unemployment and trauma in US were risk factors in Y1 and Y2,

- Holding high school or more was risk factor at BLD and having daily life problems was a risk factor at Y1.

Table 3 also reveals the overall regression of self-rated health (SRH) was significant for each of the three-year periods studied, for BLD, $\mathrm{R}=0.078, \mathrm{~F}=3.788, \mathrm{P}<0.000$, for $\mathrm{Y} 1, \mathrm{R}=0.097, \mathrm{~F}=3.754, \mathrm{P}<0.000$, for $\mathrm{Y} 2, \mathrm{R}=0.081, \mathrm{~F}=3.016, \mathrm{P}<0.000$, the predicting risk factors of likelihood excellent health in each of the three period studied revealed the following:
- $\quad$ Old age and all CD at BLD,

- Smokers and being single/divorce/widow/separate in Y1,

- Daily life problems in Y2.

However, a binary logistic regression analysis was apply for each $\mathrm{CD}$ to understand more about the predict risk factors for each of the $10 \mathrm{CD}$ reported in Y2. Results show the numbers of predictors for the $10 \mathrm{CD}$ as follows:

- Old age was a factor in all CD except obesity and depression,

- Unemployed status was factors in in 4 CD (hypertension, diabetes, MSDs and have high cholesterol),

- Trauma in US was factors in in 4 CD (diabetes, arthritis, MSDs and obesity), depression),

Daily life problems were a factor in 2 CD (MSDs and

- Some other factors were predictor with other or alone on one $\mathrm{CD}$ only such as: back home trauma in hypertension, being at high school or less education in MSDs, current stressor in depression.

\section{Discussion}

To our knowledge this is the first cohort study based on a random sample, which examines the prevalence rate of $10 \mathrm{CD}$ (Hypertension, Heart disease, Diabetes, Asthma, Arthritis, Musculoskeletal disorders (MSDs), skin disorders, high cholesterol level, obesity and depression) and their risk factors, along with self-rated health among Iraqi refugees who have recently arrived to the US (mean= one month, $\mathrm{SD}=1.09$ ). The hypotheses of the study speculated that Iraqi refugees would report no significant changes after a two-year follow-up. This hypothesis was rejected as the prevalence rate of all CD rose from $43.3 \%$ at BLD to $57.2 \%$ in Y2; the results of the study indicate that there were significant differences $(\mathrm{P}<0.001)$ in the prevalence rates for all $C D$ whether combined or tested as single diseases between baseline data (BLD), Y1, and Y2 follow-up (Table 2), but not between male and females in most diseases.

However, in general there were no significant differences between a refugee's gender and year studied in most of their variables (table 1), except in the following:

- Smoking status and alcohol status in all periods studied,

- Employment status and Marital status in Y1 and Y2,

- Back home trauma in Y1.

Linear regression analysis of the likelihood that all CD predicts their risk factor was performed (Table 3).

Furthermore, linear regression analysis (table 3) predicts different risk factors for the SRH tested in each period studied. The following risk factors were predictors in the three periods: old age among all $\mathrm{CD}$ in BLD; being single/divorce/widow/separate and smokers were a predictor in Y1; daily life problem was predictor in $\mathrm{Y} 2$.

Binary logistic regression analysis of the likelihood each CD predicts their risk factor was reported in the results. It is of interest to see the predicting risk factors in certain diseases but not in others is as follows:

- $\quad$ Old age was a factor in $8 \mathrm{CD}$, 
- Unemployed status and trauma in US were factors in in $4 \mathrm{CD}$,

- Daily life problems were a risk factor in $2 \mathrm{CD}$

- Being at high school or less education, and back home trauma were factors in at least one $\mathrm{CD}$ (different for each predictor).

It is of interest to note that the predicting risk factor of 7 out of $10 \mathrm{CD}$ were more or less the same risk factors (trauma in US, current stress and daily life problems). This should be considered in any future program for intervention in relation to $\mathrm{CD}$.

However, the results reject the second part of our hypotheses, which stated that refugees would report better health with a follow-up study. In fact, we found an increase in the number of risk factors after BLD; in particular, daily life problems in US increased the most. This was also shown when the results of linear regression analyses (table 3), for excellent to good health, revealed that individuals rated their health worse in all the periods studied, especially in Y2 where the main predictor was daily life problems in the US. We noted that the numbers of CD increases as time in the US increases. In general, the results of this study differ from previous studies because it was based on a random sample of newly arrived refugees to the US. It differs even from other Iraqi refugee's studies such as the International Organization for Migration study, which was carried out among Iraqi refugees in Jordan [14]; or in California studies [16]; of Iraqi adults; or from examining the medical records of Iraqi refugees and comparing them to refugees from the urban Northeast [18].

The percentage of Iraqi refugees who in our study reported one or more CD was $57.2 \%$ at Y2, which is higher than $27 \%$ in International Organization for Migration Jordan study [14] and 51\% in the California study [34]. It was of interest to find that Iraqi refugees in our study reported a lower prevalence rate in all CD except in arthritis (Table 2) when compared to the US general population [33--40,42,52], keeping in mind that there was significant difference between males and females in all ten CD studied, and in all periods studied except in the BLD for skin disorders.

Also, it is of interest to find in our study that $57.2 \%$ of the study populations have at least one CD (table 2) compared to $50 \%$ of the US general population [32]. Such results could raise a question about the reasons of such high prevalence rates of $\mathrm{CD}$ at Y2 compared to BLD of CD (43.3\%) among newly arrived refugees. It is worth noting the possibility of some risk factors that lead to such increases in the number of CD; E.g. exposure to daily life problems, trauma in US, current stressor, and for reasons we don't know, although the prevalence of any single $\mathrm{CD}$ was below the US general population. Numbers of $\mathrm{CD}$ rose in Y1, which could be due to health insurance leading to earlier and better diagnoses. It could also be due to factors related to unknown reasons that require a more comprehensive epidemiological study.

Study limitation and strengths: This study has key advantages over previous research, including sufficient statistical power; a randomly selected sample of newly arrived refugees in the US. Withdrawal of the participants from the study over time was very low; 298 refugees were recruited at base line, 7 withdrew in Y1, and 5 in Y2 (97\% retention rate over the three year follow-up). Major strength is the inclusion of both self-reported health and clinically diagnosed CD. An added strength of the study was as follows: filling of the survey was done by the participants through a constructive interview, with an outreach research assistant who holds a Master's degree in Public health. Despite these methodological advances, there are several limitations that should be considered. The main limitation of the study includes a sample of Iraqi refugees that may only represent one distinct group.

\section{Conclusion}

Our hypotheses, which predicted that Iraqi refugees would report either a similar prevalence rate of $\mathrm{CD}$ over the three periods studied (two year follow-up), or report a non-significant difference, was rejected. The study shows that there were significant differences in the prevalence rates for all CD between the periods studied, but no differences between males and females in any year studied. Binomial logistic regression analysis predicts risk factors for each CD in Y2; the risk factors may be the same in some diseases. The main predictor was unemployment, which shares factors in 4 out of 10 diseases; trauma in US, and current stressor and daily life problems in US. Linear regression analysis for the all $\mathrm{CD}$ in each of the three periods studied predicted risk factors for each period; the risk factors may share some or none at all in the period studied. The main predictions were old age, unemployment, and trauma in US. The study results reject the second hypotheses, which stated that refugees will report excellent to good health according to the time stayed in US as shown by the linear regression analyses.

\section{Acknowledgements}

All authors were partly supported by Award Number R01MH085793 from the National Institute of Mental Health. The content is solely the responsibility of the authors and does not necessarily represent the official views of the National Institute of the Mental Health or the National Institutes of Health

\section{References}

1. Proposed refugee admissions for fiscal year 2014, report to the Congress (2014) Department of Home Land Security.

2. Jamil H, Hakim-Larson J, Farrag M, Kafaji T, Duqum I, et al. (2002) A retrospective study of Arab American mental health clients: trauma and the Iraqi refugees. Am J Orthopsychiatry 72: 355-361. [Crossref]

3. Jaber LA, Brown MB, Hammad A, Nowak SN, Zhu Q, et al. (2003) Epidemiology of diabetes among Arab Americans. Diabetes Care 26: 308-313. [Crossref]

4. Jaber LA, Brown MB, Hammad A, Zhu Q, Herman WH (2003) Lack of acculturation is a risk factor for diabetes in arab immigrants in the US. Diabetes Care 26: 20102014. [Crossref]

5. Jamil H, Hakim-Larson J, Farrag M, Kafaji T, Jamil LH, et al. (2005) Medical complaints among Iraqi American refugees with mental disorders. J Immigr Health 7: 145-152. [Crossref]

6. Kinzie D, Riley C, McFarland B, Hayes M, Boehnlein J, et al. (2008) High prevalence rates of diabetes and hypertension among refugee psychiatric patients. $J$ NervMent Dis 196: 108-112.

7. Shara N, Carter E, Abu-Bader S, Deshields Fokar A, \& Howard B (2010). Cardiovascular disease risk factors in Arab Americans living in Metropolitan Washington, DC. CurrCardiovasc Risk Rep 4: 181-185.

8. Dookeran NM, Battaglia T, Cochran J, Geltman PL (2010) Chronic disease and its risk factors among refugees and asylees in Massachusetts, 2001-2005. Prev Chronic Dis 7: A51. [Crossref]

9. Mateen F, Carone M, Al-Saedy H, Nyce S, Ghosn J, Mutuerandu T, \& Black R (2012) Medical conditions among Iraqi Refugees in Jordan: data from the United Nations Refugee Assistance Information System. Bulletin of the World Health Organization 90: 444-451.

10. Centers for Disease Control and Prevention (CDC) (2006) Prevalence of doctordiagnosed arthritis and arthritis-attributable activity limitation--United States, 2003 2005. MMWR Morb Mortal Wkly Rep 55: 1089-1092. [Crossref]

11. Leung R1 (1996) Asthma and migration. Respirology 1: 123-126. [Crossref]

12. Giese, Amanda (2010). An Assessment of the Health of Iraqi Refugees in Chicago. Heartland Alliance. 
13. World Health Organization (2011) Non-Communicable Disease Profile: Iraq. World Health Organization.

14. Yanni EA,Naoum M, Odeh N, Han P, Coleman M, et al. (2013) The health profile and chronic diseases comorbidities of US-bound Iraqi refugees screened by the International Organization for Migration in Jordan: 2007-2009. J Immigr Minor Health 15: 1-9. [Crossref]

15. Emad (2012) The Health Profile and Chronic Diseases Comorbidities of US-Bound Iraqi Refugees Screened by the International Organization for Migration in Jordan 2007-2009.

16. Centers for Disease Control and Prevention (CDC) (2010) Health of resettled Iraqi refugees --- San Diego County, California, October 2007-September 2009. MMWR Morb Mortal Wkly Rep 59: 1614-1618. [Crossref]

17. CDC MMWR (2011) Vital Signs: Prevalence, Treatment, and Control of High Levels of Low-Density Lipoprotein Cholesterol --- United States, 1999--2002 and 20052008 60. Weekly 109-114.

18. Yun K,Hebrank K, Graber LK, Sullivan MC, Chen I, et al. (2012) High prevalence of chronic non-communicable conditions among adult refugees: implications for practice and policy. J Community Health 37: 1110-1118. [Crossref]

19. Jamil H,Hamdan TA, Grzybowski M, Arnetz BB (2011) Health effects associated with geographical area of residence during the 1991 Gulf War: a comparative health study of Iraqi soldiers and civilians. US Army Med Dep J Jul-Sep:87-96. [Crossref]

20. Proctor SP,Heeren T, White RF, Wolfe J, Borgos MS, et al. (1998) Health status of Persian Gulf War veterans: self-reported symptoms, environmental exposures and the effect of stress. Int J Epidemiol 27: 1000-1010. [Crossref]

21. The Iowa Persian Gulf Study Group (1997) Self-reported illness and health status among Gulf War veterans: A population-based study. JAMA 277: 238-245. [Crossref]

22. Simmons R, Maconochie N, Doyle P (2004) Self-reported ill health in male UK Gulf War veterans: a retrospective cohort study. BMC Public Health 4: 27. [Crossref]

23. Thomas HV,Stimpson NJ, Weightman A, Dunstan F, Lewis G (2006) Pain in veterans of the Gulf War of 1991: a systematic review. BMC MusculoskeletDisord 7: 74. [Crossref]

24. Israeli E (2012) Gulf War Syndrome as a part of the autoimmune (autoinflammatory) syndrome induced by adjuvant (ASIA).Lupus 21: 190-194. [Crossref]

25. Kelsall HL, McKenzie DP, Forbes AB, Roberts MH, Urquhart DM, et al. (2014) Painrelated musculoskeletal disorders, psychological comorbidity, and the relationship with physical and mental well-being in Gulf War veterans. Pain 155: 685-692. [Crossref]

26. [No authors listed] (1994) The Persian Gulf experience and health. NIH Technology Assessment Workshop Panel. JAMA 272: 391-396. [Crossref]

27. Presidential Advisory Commission on Gulf War Veterans (1996) Illness. Final Report. .Washington DC: US Government Printing Office.

28. Malone JD, Paige-Dobson B, Ohl C, DiGiovanni C, Cunnion S, Roy MJ (1996). Possibilities for unexplained chronic illnesses among reserve units deployed in Operation Desert Shield/Desert Storm. South Med J89:1147-1155. [Crossref]

29. Wolfe J, Proctor SP, Erickson DJ, Heeren T, Friedman MJ, et al. (1999) Relationship of psychiatric status to Gulf War veterans' health problems. Psychosom Med 61: 532540. [Crossref]

30. Hoy D, Bain C, Williams G, March L, Brooks P, et al. (2012) A systematic review of the global prevalence of low back pain. Arthritis Rheum 64: 2028-2037. [Crossref]

31. Murphy LB, Helmick CG, Allen KD, Theis KA, Baker NA, et al. (2014) Arthritis among veterans - United States, 2011-2013. MMWR Morb Mortal Wkly Rep 63: 9991003. [Crossref]

32. Wu SY, Green A (2000) Projection of chronic illness prevalence and cost inflation.
Santa Monica, CA: RAND Health; 2000

33. Keenan NL,Rosendorf KA; Centers for Disease Control and Prevention (CDC) (2011) Prevalence of hypertension and controlled hypertension - United States, 2005-2008. MMWR Suppl60: 94-97. [Crossref]

34. Centers for Disease Control and Prevention (CDC) (2010) Health of resettled Iraqi refugees --- San Diego County, California, October 2007-September 2009. MMWR Morb Mortal Wkly Rep 59: 1614-1618. [Crossref]

35. NDIC (National Diabetes Information Clearinghouse) (2011). National Diabetes Statistics.

36. Frazier JC, Loveland KM, Zimmerman HJ, Helgerson SD, Harwell TS (2012) Prevalence of asthma among adults in metropolitan versus nonmetropolitan areas in Montana, 2008. Prev Chronic Dis 9: E09. [Crossref]

37. Centers for Disease Control and Prevention (CDC) (2010) Prevalence of doctordiagnosed arthritis and arthritis-attributable activity limitation --- United States, 2007 2009. MMWR Morb Mortal Wkly Rep 59: 1261-1265. [Crossref]

38. Le Q, Kreckmann, Starks, J-Morel (2013) Prevalence of musculoskeletal disorders among US employees of a large company. Occup Environ Med 70: A31.

39. Hay RJ, Johns NE, Williams HC,Bolliger IW,Dellavalle RP4, et al. (2014) The globa burden of skin disease in 2010: an analysis of the prevalence and impact of skin conditions. J Invest Dermatol 134: 1527-1534. [Crossref]

40. Mozaffarian D, Benjamin EJ, Go AS, Arnett DK, Blaha MJ, et al. (2015) Heart disease and stroke statistics--2015 update: a report from the American Heart Association. Circulation 131: e29-322.[Crossref]

41. CDC (2013) Behavioral Risk Factor Surveillance BRFSS System.

42. Major Depression Among Adults (2014) NIMH.

43. Arnetz J,Rofa Y, Arnetz B, Ventimiglia M, Jamil H (2013) Resilience as a protective factor against the development of psychopathology among refugees. $J$ NervMent Dis 201: 167-172.[Crossref]

44. Arnetz BB,Broadbridge CL, Jamil H, Lumley MA, Pole N, et al. (2014) Specific trauma subtypes improve the predictive validity of the Harvard Trauma Questionnaire in Iraqi refugees. J Immigr Minor Health 16: 1055-1061. [Crossref]

45. Arfken CL,Broadbridge CL, Jamil H, Arnetz BB (2014) Immigrant Arab Americans and alcohol use: longitudinal study. J Immigr Minor Health 16: 1303-1306. [Crossref]

46. Jen KL, Zhou K, Arnetz B, Jamil H (2015) Pre- and Post-displacement Stressors and Body Weight Development in Iraqi Refugees in Michigan. J Immigr Minor Health 17: 1468-1475. [Crossref]

47. Wright AM,,Aldhalimi A, Lumley MA, et al. (2015) Determinants of resource needs and utilization among refugees over time. Soc Psychiatry PsychiatrEpidemiol . [Crossref]

48. CDC (Centers for Disease Control and Prevention) (2006). National Health Interview Survey.

49. Mollica RF,Caspi-Yavin Y, Bollini P, Truong T, Tor S, et al. (1992) The Harvard Trauma Questionnaire. Validating a cross-cultural instrument for measuring torture, trauma, and posttraumatic stress disorder in Indochinese refugees. J NervMent Dis 180: 111116. [Crossref]

50. Shoeb M, Weinstein HM, Halpern J (2007). Living in religious time and space: Iraqi refugees in Dearborn, Michigan. J Refug Stud 20: 441-460.

51. Kanner AD, Coyne JC, Schaefer C, Lazarus RS (1981) Comparison of two modes of stress measurement: daily hassles and uplifts versus major life events. J Behav Med 4: 1-39. [Crossref]

52. Annual Survey Data(2014) BRFSS (The Behavioral Risk Factor Surveillance System), USA.

Copyright: (C2016 Jamil H. This is an open-access article distributed under the terms of the Creative Commons Attribution License, which permits unrestricted use, distribution, and reproduction in any medium, provided the original author and source are credited. 